\title{
Use of Oral Antihypertensive Medication Preceding Blood Pressure Elevation in Hospitalized Patients
}

\author{
Cristiano Ricardo Bastos de Macedo, Antonio Carlos Beisl Noblat, Lúcia de Araújo Costa Beisl Noblat, \\ Jeane Meire Sales de Macedo, Antonio Alberto Lopes
}

Salvador, BA - Brazil

\begin{abstract}
Objective - To evaluate the frequency of oral antihypertensive medication preceding the increase in blood pressure in patients in a university hospital, the drug of choice, and the maintained use of antihypertensive medication.
\end{abstract}

Methods - Data from January to June 1997 from the University Hospital Professor Edgard Santos Pharmacy concerning the prescriptions of all inpatients were used. Variables included in the analysis were: antihypertensive medication prescription preceding increase in blood pressure, type of antihypertensive medication, gender, clinical or surgical wards, and the presence of maintained antihypertensive medication.

Results - The hospital admitted 2,532 patients, 1,468 in surgical wards and 818 in medical wards. Antihypertensive medication prescription preceding pressure increase was observed in 578 patients (22.8\%). Nifedipine was used in 553 (95.7\%) and captopril in 25 (4.3\%). In 50.7\% of patients, prescription of antihypertensive medication was not associated with maintained antihypertensive medication. Prescription of antihypertensive drugs preceding elevation of blood pressure was significantly $(p<0.001)$ more frequent on the surgical floor $(27.5 \%$; 405/1468) than on the medical floor $(14.3 \% ; 117 / 818)$. The frequency of prescription of antihypertensive drugs preceding elevation of blood pressure without maintained antihypertensive drugs and the ratio between the number of prescriptions of nifedipine and captopril were greater in surgical wards.

Conclusion - The use of antihypertensive medication, preceding elevation of blood pressure (22.8\%) observed in admitted patients is not supported by scientific evidence. The high frequency of this practice may be even greater in nonuniversity hospitals.

Key words: hypertension, nifedipine, captopril

Hospital Universitário Professor Edgard Santos - Universidade Federal da Bahia Mailing address: Antonio Alberto Lopes - Rua Marechal Floriano, 448/1301 40110-010 - Salvador, BA - E-mail: aaslopes@ufba.br
Asymptomatic elevation of systemic blood pressure is an expected event in a determined percentage of hospitalized patients, taking into account the emotional conditions that occur in disease-related admittance, characterizing hypertensive pseudo emergencies. Individually, this blood pressure elevation is not a matter of using antihypertensive medication ${ }^{1}$. It is also important to observe that hypertensive patients experience a decrease in blood pressure after being admitted to the hospital regardless of the treatment ${ }^{2-5}$.

In the last 2 decades, antihypertensive medications that act quickly after oral or sublingual administration ${ }^{6-12}$ have been used. The ease of administering such drugs contributes to their prescription before elevation of blood pressure. However, the safety and real benefit of this procedure has not been supported by scientific evidence ${ }^{1,13-15}$. In fact, severe complications related to the use of these medications have been reported ${ }^{1,16-20}$. The purpose of this study was to assess the frequency of oral prescription of antihypertensive medication before elevation of blood pressure in an academic hospital. We compared the frequency of this type of prescription on a medical and a surgical floor.

\section{Methods}

Data from all patients admitted to the Hospital Universitário Professor Edgard Santos Universidade Federal da Bahia were retrospectively assessed between January and July 1997. According to data obtained from the Medical Files and Statistics, 2,532 patients were admitted to the University Hospital during this period. Data assessment was done systematically through a form previously elaborated. Data from the files of the hospital pharmacy corresponding to all medical prescriptions of admitted patients during the study period were surveyed. We defined the presence of a written item in the medical records consenting to the use of oral antihypertensive medication when blood pressure reached a certain level as antihypertensive prescription before elevation of blood pressure. Data concerning sex, type of floor where the patient was hospitalized [(medical, surgical, 
pediatric floor or Intensive Care Unit (ICU)], type of drug prescribed as antihypertensive before elevation of blood pressure (nifedipine, captopril, or clonidine)] were recorded and also whether any concurrent prescription existed of any maintained antihypertensive medication. Through the pharmacy records, it was not possible to know the age of the patient and if whether the medication had been administered. For a comparative analysis, we considered only the patients admitted to medical or surgical wards, because patients may be admitted to the pediatric floor and ICU with both clinical and surgical emergencies.

Data assessment was performed with the Statistical Program for Social Science, (SPSS), version 6.1 for Windows ${ }^{21}$. Statistical significance for differences in proportion was estimated with the chi-square test or Fisher's exact test. All tests were two-tailed analyses with 5\% of type error probability.

\section{Results}

Of the 2,532 patients admitted, prescription of antihypertensive medication preceding elevation of blood pressure was observed in 578 (22.8\%). In this group of patients, where antihypertensive medication was prescribed preceding elevation of blood pressure, 297 (51.4\%) were men, and $281(48.6 \%)$ were women. One hundred and seventeen (20.2\%) patients were admitted to clinical wards, 405 $(70.1 \%)$ were admitted to surgical wards, $9(1.6 \%)$ were admitted to the pediatric floor, and $46(8 \%)$ were admitted to the ICU. We could not identify the location of 1 patient in the hospital. Nifedipine was the medication given before elevation of blood pressure in 553 (95.7\%) patients and captopril in $25(4.3 \%)$. Clonidine was not prescribed during the study period. In 293 (50.7\%) patients, prescription of antihypertensive medication before elevation of blood pressure occurred in the absence of treatment with maintained antihypertensive therapy.

Of the patients hospitalized during the period of the survey, $58.2 \%$ (1473/2532) were from the surgical wards, and $32.3 \%$ (818/2532) were from the clinical wards. The frequency of prescription of antihypertensive medication preceding elevation of blood pressure was significantly higher $(\mathrm{p}<0.001)$ in surgical wards $(27.5 \%$; 405/1473) than in clinical wards $(14.3 \% ; 117 / 818)$. We also observed that, in patients who were prescribed antihypertensive medication before elevation of blood pressure, nifedipine was the medication of choice in $89.7 \%$ (105/117) of patients from the clinical wards and in 96.8\% (392/405) of patients from the surgical wards $(\mathrm{p}<0.002)$. Of patients without maintained antihypertensive medication who were prescribed antihypertensive treatment preceding elevation of blood pressure, 55.8\% (226/405) were surgical patients and 33.3\% (39/117) were clinical patients $(\mathrm{p}<0.001)$.

Data presented are also useful to assess the influence of the medication prescribed as an antihypertensive medication before the elevation of blood pressure and the concurrent prescription of maintained antihypertensive medica- tion. We observed that $52.4 \%$ (290/553) and $12.0 \%$ (3/25) of patients who were prescribed, respectively, nifedipine and captopril as antihypertensive medication before elevation of blood pressure $(\mathrm{p}<0.001)$ were not prescribed maintained antihypertensive medication. Of the surgical patients, no reference existed concerning the use of maintained antihypertensive medication in $57.1 \%(224 / 392)$ and $15.4 \%$ (2/13) of patients who were prescribed, respectively, nifedipine and captopril before elevation of blood pressure $(\mathrm{p}<0.003)$. Of clinical patients, the respective percentage were $36.2 \%$ (38/ $105)$ and $8.3 \%(1 / 12)(\mathrm{p}=0.05)$.

\section{Discussion}

Evidence that drugs that immediately reduce blood pressure are contraindicated in situations not characterized as hypertensive emergencies ${ }^{1,13,14}$ shows that the habit of prescribing antihypertensive medication preceding elevation of blood pressure, observed in this study, must be considered inadequate. It is important to note that previous studies estimate the prevalence of hypertension in hospitalized patients as between 17.4 to $28.6 \%{ }^{22-24}$. A greater prevalence of more severe forms of hypertension would be necessary to justify the concerns of the academic doctors about the risk of a hypertensive emergency in their patients. This is a reduced possibility, because admittances in the referred hospital, in general, are not motivated by urgency or emergency.

Data of the present study also show that, during the first semester of 1997, the frequency of prescription of antihypertensive medication before elevation of blood pressure was substantially greater in surgical wards, although differences between patients in both the medical and surgical floors were not clear. However, it is possible that they are in part related to different interpretations of practitioners and surgeons, regarding the adequate approach to the hypertensive patient and the peculiarities of the problems of the clinical and surgical wards ${ }^{23}$. Surgeons probably prescribe antihypertensive medication before the elevation of blood pressure because they are concerned about the development of severe swings in blood pressure during the perioperative period. According to the available evidence, however, the best conduct for the control of hypertension in this situation is the maintenance of regular antihypertensive treatment until the time of the surgical procedure and the use of intravenous antihypertensive medication in patients who experience a hypertensive emergency in the perioperative period ${ }^{25-27}$.

The greater prevalence of prescribing nifedipine preceding elevation of blood pressure-is because this has been the most extensively evaluated medication for hypertensive emergencies in the last two decades ${ }^{9,12,16,17}$. The greater frequency of nifedipine prescription occurred both in medical and surgical patients; however, prescription of captopril was significantly greater in medical patients. We could not find any prescription of clonidine before elevation of blood pressure. It is important to note, however, that the survey 
was conducted in 1997. The reports showing evidence against the use of nifedipine may be influencing doctors to modify their behavior concerning the prescription of antihypertensive medication preceding the elevation of blood pressure. Data presented are important for comparison with the studies to be developed in the future.

Even if the results of future comparative studies, when compared with the results of the present study, show that doctors are changing their procedures, it will be important to consider that just the replacement of 1 drug for another (for instance, captopril instead of nifedipine) as antihypertensive medication preceding elevation of blood pressure does not mean that the doctor is properly acting in the treatment of the hospitalized hypertensive patients. It is of utmost importance to use the admittance of the hypertensive patient as an opportunity to recognize a suitable treatment for blood pressure control and to initiate the follow-up of hypertensive patients ${ }^{23}$. Elevation of blood pressure occurs every day in patients with mild hypertension that are not properly controlled ${ }^{28}$. Furthermore, elevation of systemic blood pressure, which is not a hypertensive emergency, does not require an immediate decrease in blood pressure ${ }^{1,29}$.

The present study suggests that physicians frequently fail to capitalize on hospitalization as an opportunity to find the best therapeutics for the patient. In most cases, the concern about prescribing antihypertensive medication preceding elevation of blood pressure was not followed by the use of maintained antihypertensive medication. This type of prescription was significantly greater in surgical wards in relation to clinical wards. Some of these patients could have threshold levels of blood pressure, raising a question concerning the need for maintained medication, which does not justify, however, the prescription of antihypertensive medication preceding the elevation of blood pressure. Elevation of blood pressure in patients with such characteristics may occur for several reasons, including anxiety. Medical assessment at the time that elevation of blood pressure is detected is, therefore, essential, in the sense of adopting the most suitable conduct, based on the particularities of each situation and the scientific evidence available.

As for the relationship between prescribing antihy- pertensive medication preceding the elevation of blood pressure and adopting therapeutics for the long-term control of blood pressure, it is important to note that in the present study, we found a greater frequency of prescription of maintained antihypertensive medication in patients who were prescribed captopril, compared with those who were prescribed nifedipine preceding elevation of blood pressure. The frequency of prescriptions of maintained antihypertensive medication, in relation to the type of drug chosen as the antihypertensive medication preceding elevation of blood pressure, was similar in the clinical and surgical wards. Although the characteristics of patients may be different, data from the present study suggest that doctors that have opted for captopril as antihypertensive medication preceding elevation of blood pressure instead of nifedipine have adopted a different conduct concerning the therapeutics of maintained hypertension.

In conclusion, the results of the present study show a high frequency of prescription of antihypertensive medication preceding elevation of blood pressure. Data are of use as a warning that this conduct, besides the possible secondary complications to the rapid reduction in pressure levels, can also contribute to inadequate control of blood pressure during hospitalization, because this was the only antihypertesive treatment available in the prescriptions of $50 \%$ of the study patients. It is important to note that, although many articles have been written to discourage the oral use of drugs that immediately reduce blood pressure in situations not characterized as hypertensive emergencies ${ }^{1,16-18,20}$, we did not find studies in an extensive MEDLINE search that were conducted for the purpose of assessing whether the recommendations are being followed in medical practice. New studies should be carried out to assess whether the results of this study can be generalized to other hospitals and whether the procedures regarding the prescription of antihypertensive medication preceding elevation of blood pressure are changing, over the time. It is also important to evaluate the frequency in which patients who were prescribed antihypertensive medication preceding blood pressure elevation really receive the medication and the reasons for such a procedure.

\section{References}

1. Grossman E, Messerli FH, Grodzicki T, Kowey P. Should a moratorium be placed on sublingual nifedipine capsules given for hypertensive emergencies and pseudoemergencies? JAMA 1996; 276: 1328-31.

2. Takata Y, Tominaga M, Nakao Y, et al. Spontaneous fall in blood pressure and reactivity of sympathetic nervous system in hospitalized patients with essential hypertension. Jpn J Med 1990; 29: 13-21.

3. Hossmann V, FitzGerald GA, Dollery CT. Influence of hospitalization and placebo therapy on blood pressure and sympathetic function in essential hypertension. Hypertension 1981; 3: 113-8.

4. Nishimura H, Nishioka A, Kubo S, Suwa M, Kino M, Kawamura K. Multifactorial evaluation of blood pressure fall upon hospitalization in essential hypertensive patients. Clin Sci 1987; 73: 135-41.

5. Mills PJ, Berry CC, Dimsdale JE. Race affects the decline in blood pressure with hospitalization. Am J Hypertens 1997; 10: 1091-6.
6. Karachalios GN. Hypertensive emergencies treated with oral clonidine. Eur J Clin Pharmacol 1986; 31: 227-9.

7. Biollaz J, Waeber B, Brunner HR. Hypertensive crisis treated with orally administered captopril. Eur J Clin Pharmacol 1983; 25: 145-9.

8. Marigliano V, Santilli D, Fiorani M, et al. Hypertensive emergencies in old age: effects of angiotensin converting enzyme inhibition. J Hypertens 1988; 6: S91-3.

9. Gonzalez-Carmona VM, Ibarra-Perez C, Jerjes-Sanchez C. Single-dose sublingual nifedipine as the only treatment in hypertensive urgencies and emergencies. Angiology 1991; 42: 908-13.

10. Anderson RJ, Hart GR, Crumpler CP, Reed WG, Matthews CA. Oral clonidine loading in hypertensive urgencies. JAMA 1981; 246: 848-50.

11. Houston MC. Treatment of hypertensive emergencies and urgencies with oral clonidine loading and titration. A review. Arch Intern Med 1986; 146: 586-9. 
12. Karachalios GN, Donas G, Tsimiklis S, Stathakakis V. Treatment of hypertensive emergencies with nifedipine. Int J Clin Pharmacol Ther Toxicol 1988; 26: 351-5.

13. The sixth report of the Joint National Committee on prevention, detection, evaluation, and treatment of high blood pressure. Arch Intern Med 1997; 157: 2413-46.

14. Sociedade Brasileira de Hipertensão, Sociedade Brasileira de Cardiologia, Sociedade Brasileira de Nefrologia. III Consenso Brasileiro de Hipertensão Arterial. Arq Bras Endocrinol Metab 1999; 43: 257-86.

15. Grossman E, Ironi AN, Messerli FH. Comparative tolerability profile of hypertensive crisis treatments. Drug Saf 1998; 19: 99-122.

16. Bauer JH, Reams GP. The role of calcium entry blockers in hypertensive emergencies. Circulation 1987; 75: V174-80.

17. Bertel O, Conen LD. Treatment of hypertensive emergencies with the calcium channel blocker nifedipine. Am J Med 1985; 79: 31-5.

18. Gales MA. Oral antihypertensives for hypertensive urgencies. Ann Pharmacother 1994; $28: 352-8$

19. O'Mailia JJ, Sander GE, Giles TD. Nifedipine-associated myocardial ischemia or infarction in the treatment of hypertensive urgencies. Ann Intern Med 1987; 107: 185-6.

20. Furberg CD, Psaty BM, Meyer JV. Nifedipine. Dose-related increase in mortality in patients with coronary heart disease. Circulation 1995; 92: 1326-31.

21. Norusis MJ. SPSS for windows: base system user's guide, release 6.1. Chicago, Il: SPPS Inc., 1994
22. Shankar BS, Russell RP, Southard JW, Schurman EW. Patterns of care for hypertension among hospitalized patients. Public Health Rep 1982; 97 521-7.

23. Greenland P, Levenkron JC, Smith RM. Hospitalization as an opportunity to improve hypertension recognition and control. Med Care 1987; 25: 717-23.

24. Silva NAS, Aguiar GR, Nogueira AR, Duarte MMT, Alves RHF. Importância clínica dos custos diretos hospitalares em pacientes com hipertensão arterial em tratamento num hospital universitário. Rev Saúde Pública 1986; 20: 293-302.

25. Vertes V, Goldberg G. The preoperative patient wit hypertension. Med Clin North Am 1979; 63: 1299-1308.

26. Katz JD, Croneau LH, Barash PG. Postoperative hypertension: a hazard of abrupt cessation of antihypertensive medication in the preoperative period. Am Heart J 1976; 92: 79-80.

27. Laslett L. Hypertension. Preoperative assessment and perioperative management. West J Med 1995; 162: 215-9.

28. Sociedade Brasileira de Nefrologia, Sociedade Brasileira de Cardiologia, Sociedade Brasileira de Hipertensão. II Consenso Brasileiro para o Uso da Monitorização Ambulatorial da Pressão Arterial. Arq Bras Cardiol 1997; 69: 359-72.

29. Ferguson RK, Vlasses PH. How urgent is "urgent" hypertension? Arch Intern Med 1989; 149: 257-8

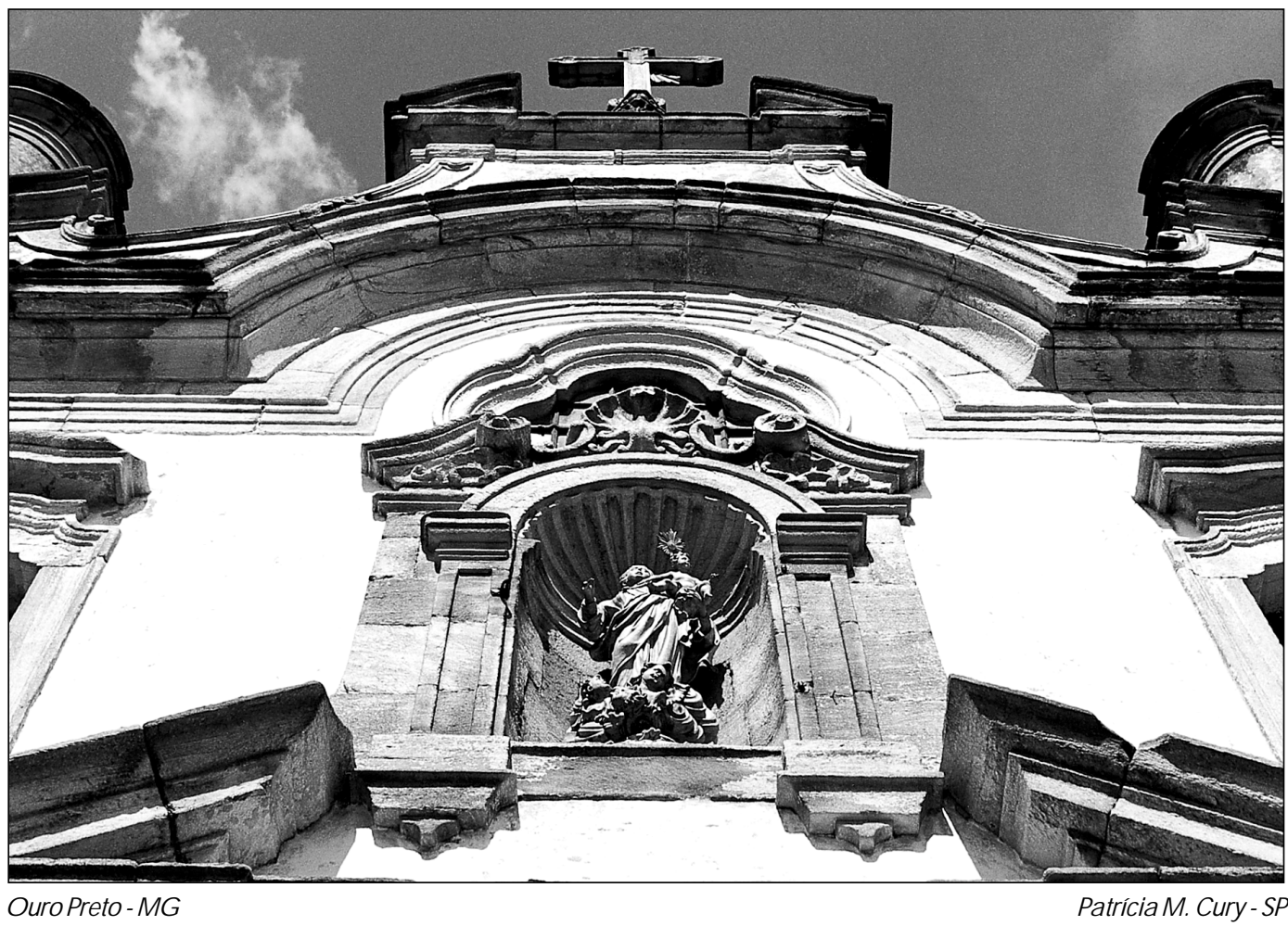

Editor da Seção de Fotografias Artísticas: Cícero Piva de Albuquerque

Correspondência: InCor - Av. Dr. Enéas C. Aguiar, 44 - 05403-000 - São Paulo, SP - E-mail: dclcicero@incor. usp.br 